\title{
LAS DIVERGENCIAS EN EL RÉGIMEN VERBAL DEL OBJETO DIRECTO E INDIRECTO EN POLACO Y EN CASTELLANO
}

\begin{abstract}
A bstract. Pawlik Janusz, Las divergencias en el régimen verbal del objeto directo e indirecto en polaco $y$ en castellano [Difference in the rection of the direct and indirect complement in Polish and Castillian]. Studia Romanica Posnaniensia, Adam Mickiewicz University Press, Poznań, vol. XXV/XXVI: 2000, pp. 235-247, ISBN 83-232-0965-0, ISSN 0137-2475.

The divergence in the use of noun objects required by certain verbs in both languages is obvious. The problem, however, becomes difficult to solve, because in Spanish it is sometimes impossible to tell the difference between the direct and indirect object in a verb group. Unlike other Romance languages, the preposition ' $a$ ' is often both the mark of accusative and dative forms. In addition, the defective pronoun forms replacing noun objects are widespread in Spain (leísmo, laísmo) and create confusion in speakers' minds. In this paper, we will try to find out the real syntactic value of some Spanish objects, usually mistaken by Polish learners of Spanish, and to draw up a list of those verbs whose objects don't agree in both languages.
\end{abstract}

Los términos de objeto directo y objeto indirecto fueron acuñados por la gramática francesa para designar a dos adyacentes que van unidos estrechamente al verbo en el marco del predicado verbal. Son los elementos obligatorios del mismo y su eliminación llevaría a enunciados anómalos o con otro significado. Este rasgo común los diferencia del complemento circunstancial que debido a su carácter marginal se puede eludir fácilmente sin que se modifique la estructura y el sentido de una oración. La denominación directo sugiere que el objeto se une al verbo directamente sin ningún enlace preposicional. Los objetos que llevan preposiciones son obviamente indirectos. Esta clasificación dicotómica se aplica a la lengua francesa y caracteriza bien a su estructura sintáctica. No obstante, el español se destaca entre las otras lenguas románicas por el empleo de la preposición $a$ ante los objetos directos de persona, es decir, el antiguo caso acusativo latino. En vista de ello, teóricamente, todos los objetos españoles deberían incluirse entre los indirectos. A pesar de esa incoherencia formal, el término de objeto directo (OD) ya se ha arraigado en la tradición española y se 
asemeja a la función desempeñada por el caso acusativo en las lenguas flexionales. La extensión del objeto indirecto (OI) está notablemente restringida en castellano al caso dativo, es decir, al sustantivo precedido siempre de la preposición $a$. Por otro lado los objetos restantes se clasifican como suplementos u objetos preposicionales y comprenden sintagmas correspondientes a otros casos latinos. Estos, gracias a su forma distinta, son fáciles de reconocer y no plantean graves problemas de delimitación.

El problema surge cuando tenemos que ver con dos objetos formalmente iguales. Según se ha dicho tanto el OI como el OD de persona admitenel mismo índice $a$, lo cual puede producir posible confusión en la adecuada interpretación del comunicado. En la oración El maestro presentó a su mujer a Juan suele interpretarse que el primero de los dos adyacentes pospuestos al verbo funciona como OD y el segundo como OI. Sin embargo la construcción es ambigua y los equívocos se evitan solo introduciendo pronombres personales átonos: Se la presentó a Juan o Se lo presentó a su mujer (Alarcos 1994: 280).

En la gramática polaca la noción de OD (dopełnienie bliższe) va asociada a la forma del caso acusativo y la de OI (dopełnienie dalsze) recubre los complementos no circunstanciales expresados por los demás casos. Por razones metodológicas, en el presente escrito, definiremos el último en cuanto la persona, animal o cosa que recibe el beneficio o perjuicio de la acción verbal, o sea, lo limitaremos al llamado caso dativo. De esta manera su contenido será atribuible a su dimensión española. En las lenguas románicas la diferenciación entre OD y OI se lleva a cabo explícitamente mediante las distintas marcas formales. La presencia o ausencia de la preposición $a$ delante de uno de los complementos es un indicio infalible de su función oracional. Comprobémoslo en lo que sigue:

J'ai donné une pomme a Pierre. (OD + OI)

Ho dato una mela a Pietro. (OD + OI)

Esta información resulta particularmente útil para alumnos de francés e italiano como lengua extranjera, por cuanto en caso de conmutación saben qué referente personal átono debería emplearse en lugar de los sustantivos. Así las frases anteriores pueden sustituirse por:

Je la lui ai donné.

Gliel'ho data.

En este caso y en la mayoría de los otros, las lenguas romances confluyen con la polaca en asignar las mismas funciones a sus adyacentes verbales y, en principio, no debería plantear problemas su debida interpretación; pero naturalmente no siempre es así. Numerosos son los ejemplos de desacuerdo donde algunos verbos polacos rigen otros objetos que sus correlatos románicos. Lo atestiguan dos pares de frases en polaco y en francés: 
(1) J'ai demandé à Jacques de se tenir à l'écart = (1a) Je le lui ai demandé. Poprosiłem Jakuba, żeby trzymał się od tego $\mathrm{z}$ daleka = Poprosiłem go o to.

(2) J'aidais mon frère quand il était malade $=(2 a)$ Je $l$ 'aidais quand il était malade.

Pomagałem memu bratu, gdy był chory = Pomagałem $m u$, gdy był chory.

Bien es sabido que a diferencia del francés, el verbo polaco pomagać admite un dativo y prosić, un acusativo, y no al revés. $Y$ efectivamente es muy frecuente que alumnos principiantes incurran en esta incorrección sintáctica por imitar mecánicamente el modelo de su lengua nativa. Sin embargo, y hay que ponerlo muy claro, este desacierto puede ser evitado al examinar atentamente el régimen casual de los objetos en las secuencias aducidas arriba. En definitiva, no solo los pronombres casuales lui (1a) y le (2a), sino también la forma del sintagma nominal entero; à Jacques (1) y mon frère (2) son exponentes suficientes y adecuados para la oportuna adscripción de sus papeles.

\section{LA AMBIGÜEDAD DEL SISTEMA CASTELLANO}

Pero no ocurre lo mismo en castellano donde, como indicábamos, OD y OI llevan neutralizada la oposición, coincidiendo el OD de persona con la marca de dativo. Comparemos:

Di una manzana a Pedro. (OI)

Vi a Pedro cuando caminaba por el parque. (OD)

Al desaparecer cualquier diferencia formal, presumimos, por el contenido semántico, que el primer adyacente viene a cumplir la función de indirecto y el segundo, la de directo respecto de los verbos dar y ver. Este supuesto lo confirma la prueba de pronominalización consistente en representar los sintagmas sustantivas por sus referentes pronominales átonos de 3 a persona, el mejor expediente para reconocer su verdadero carácter sintáctico. En el español modélico, el OD se expresa por los pronombres lo, la (singular) y los, las (plural) y el OI admite las formas comunes sin discriminación de género le, les. Efectuada la conmutación, las oraciones aludidas adquieren la forma siguiente:

Le di una manzana. (OI)

$L o$ vi cuando caminaba por el parque. (OD)

El sistema originario de los pronombres personales, tal y como lo hemos expuesto arriba, viene usándose en la variedad americana del castellano y en las zonas meridionales de España. Es el uso más extendido en el dominio de habla española y se lo recomienda en el registro culto de la lengua. A pesar de ello, hay varios territorios 
de la Península, incluida la capital de España, en que el uso popular y en ocasiones también el uso coloquial medio se atienen a unos empleos de los pronombres personales átonos que distan de los normales. Entre ellos está permitido y aceptado por la Academia el llamado leísmo, o mejor dicho uno de sus tipos. Este consiste en el empleo de $l e$, y con menor frecuencia de su plural les, como referentes del oficio de OD cuando se refiere a persona del género masculino. Se produce así una confusión total con el pronombre objeto indirecto. Veámoslo en un ejemplo:

Le vi en el bar. (OD)

Le tomé una foto. (OI)

Les has dejado en medio de la carretera. (OD)

¿Les pediste un beso? (OI)

Este esquema alterna con el uso etimológico, y es sobre todo el más corriente entre escritores castellanos y leoneses. El uso defectuoso de los pronombres masculinos de persona aparece pronto y se generaliza desde el s. XIV estableciendo distinción entre la alusión a persona le y lo que no es persona lo. Así:

Le vi en el bar. (OD de persona)

Levanté el bolígrafo y lo puse en la silla. (OD de cosa)

No rechazado por la norma académica este fenómeno lingüístico es un compromiso entre el uso conservador y las tendencias posteriores del idioma (Alarcos 1994: 202). Se ha señalado como causas de dicha transgresión la homonimia de lo masculino y lo neutro en el uso primitivo y la analogía con la distinción genérica en el pronombre sujeto o en el demostrativo. Considérese el cuadro con las formas análogas:

$\begin{array}{lll}\text { Masculino } & \text { Femenino } & \text { Neutro } \\ \text { el(le) } & \text { ell-a } & \text { ell-o } \\ \text { est-e } & \text { est-a } & \text { est-o } \\ \text { es-e } & \text { es-a } & \text { es-o } \\ l-e & l-a & l-o\end{array}$

Esto explica que se produzca solo en masculino y con mayor intensidad en singular le que en plural les donde no hay la necesidad de distinguir el neutro (Alcina, Blecua 1975: 607), por ejemplo:

Había que sacarlos de sí, provocarlos, amedrentarlos.

Se quedó mirandole sin atreverse a hablar.

De lo antes dicho se desprende que debido a la confluencia de las formas pronominales, ni siquiera la pronominalización de los sintagmas masculinos de persona sirve para clasificar debidamente los objetos. En vista de los problemas esbozados es siempre aconsejable atenerse a la norma etimológica donde se mantiene firme y 
clara la oposición de funciones en las unidades de tercera persona; los pronombres de otras personas, teniendo una sola forma para OD y OI (me, te, se, nos, os), no nos sirven de apoyo. Para evitar la posible confusión, los ejemplos ofrecidos a continuación serán tomados del español estándar no leísta.

Es preciso advertir que el pronombre personal femenino, por ser menos susceptible de sufrir esta imperfección, constituye un punto de referencia más adecuado y seguro en nuestro análisis. Nótense las diferentes formas pronominales atribuidas a dos funciones distintas:

No queréis ayudarla porque es pobre.

Le pregunté a la enfermera si tenía un día libre.

Al pasar por la plaza les pedí un cigarrillo a las jóvenes.

Estos significantes átonos proporcionan información atinada acerca del régimen casual de los verbos en cuestión, incluido el uso leísta, y su prueba de conmutación da el mejor resultado. Es evidente que las frases ayudar a Carmen, pedir a las jóvenes o preguntar a la enfermera son equívocas, pero no lo son sus transformaciones ayudarla, pedirles y preguntarle. Como se puede apreciar, el régimen verbal de los objetos no se ajusta al requerido por los verbos polacos pomagać jej, prosić je y pytać ja. El pronombre acusativo en los dos últimos no coincide con los significantes castellanos de dativo. Al revés, pomagać exige un $\mathrm{OI}$ (jej, jemu), mientras que ayudar siempre se acompaña de un OD (la, lo). Veámoslo otra vez:

Spytałem Janka o najnowsze wiadomości. (OD)

(3) Le pregunté a Juan las últimas noticias. (OI)

Myślę, że jest moim obowiązkiem pomóc mu. (OI)

Creo que es mi deber ayudarlo. (OD)

\section{RÉGIMEN CASUAL EN LOS VERBOS CON DOS OBJETOS}

Como vemos, el verbo del ejemplo (3) exige dos complementos: a Juan y las últimas noticias. Por regla general, cuando uno de ellos es OD, el otro suele ser OI en español y objeto preposicional (suplemento) en polaco. Los verbos españoles admiten raramente Oprep. y OD en un mismo predicado. De ahí que la presencia de un acusativo acarree mayoritariamente la de un dativo. En este tipo de verbos el receptor de la acción es una cosa y su destinatario, una persona. Por ello se reducen preferentemente al esquema preguntar algo a alguien, que no da lugar a ambigüedades siendo los dos objetos bien delimitados. Seguidamente presentamos una lista de verbos que requieren dos objetos y cuyo régimen es distinto del polaco:

asegurar algo a alguien = zapewniać o czymś kogoś

comprar algo a alguien = kupować coś u kogoś

comunicar algo a alguien = powiadomić o czymś kogoś, zakomunikować coś komuś 
enseñar algo a alguien = uczyć czegoś kogoś, pokazywać coś komuś informar de algo a alguien = informować o czymś kogoś

pedir algo a alguien = prosić o coś kogoś

preguntar algo a alguien = pytać o coś kogoś

rogar algo a alguien = prosić o coś kogoś, modlić się o coś do kogoś

solicitar algo a alguien = ubiegać się o coś u kogoś, blagać o coś kogoś

suplicar algo a alguien = błagać o coś kogoś

En los verbos transcritos el objeto de persona es de tipo indirecto en castellano y directo en polaco. Empléense ahora estas unidades en oraciones compuestas de manera que los OD de cosa castellanos se conviertan en oraciones subordinadas sustantivas:

Le aseguro que el aparato tiene garantía de seis meses. (OI + OD)

Me han preguntado si tengo tiempo. (OI + OD)

Les pedí a las chicas que me esperaran a la puerta. (OI + OD)

Bien es sabido que la oración subordinada que sigue a la conjunción que y si siempre ejerce el oficio de OD. El otro complemento, si lo hay, sustituible por un pronombre, tiene que ser naturalmente OI. Así, por ejemplo, en caso de duda en cuanto a la frase informar a alguien, vale la pena recordar que el verbo referido se acompaña ordinariamente de dos complementos y que el otro puede desarrollarse en una oración subordinada sustantiva de OD:

¿Le informaste al Ministro que venías al día siguiente? (OI +OD)

Este expediente es muy sencillo y se lo aplica para los verbos con dos objetos. Por encima, la competencia linguiística que se exige al respecto no es elevada y muy bien puede recomendarse a los estudiantes desde el nivel elemental de enseñanza. Nótese al mismo tiempo que dicha regla, aunque válida para las otras lenguas romances, no encuentra su plena realización en polaco. A saber, no todas las oraciones introducidas por la preposición zeby, ze tienen carácter de sustantivas de OD. Ejemplifiquémoslo:

Je lui ai demandé de se retirer. (OI + OD)

Le he pedido que se retire. (OI + OD)

Poprosiłem go, zeby odszedt. (OD + OI)

Je lui ai enseigné qu'on ne peut pas perdre de l'esperance. (OI + OD)

Le enseñé que no se puede perder la esperanza. (OI + OD)

Nauczyłem go, ze nie mozna tracić nadziei. (OD + OI)

La situación se complica cuando algunos verbos admiten dos construcciones transitivas: con objeto directo de cosa e indirecto de persona, y con tan solo OD de persona. Repárese en el desplazamiento funcional de los complementos siguientes: 
Quiero perdonarle sus pecados. (OI)

Lo perdono (a él) porque lo hizo sin querer. (OD)

¿Le sirvo un biftec a la señora? (OI)

¿En qué puedo servirla, señora? (OD)

Lo que ocurre es que en los ejemplos transcritos un complemento de persona asume el oficio de OI cuando se alude a un complemento de cosa. En caso contrario, aquél experimenta un cambio de funciones y puede (aunque es optativo) expresarse por un acusativo'. El uso vacilante demuestra que el régimen casual de estos verbos no está fijado y su fluctuación va contrastando con la estabilidad del sistema en polaco. Compruébese la inviabilidad del procedimiento expuesto aplicado a este último idioma:

Poradziłem $m u$ dobrego lekarza.

*Poradziłem go w trudnym momencie.

Aparte de las transgresiones indicadas, los verbos españoles mantienen en principio estables sus complementos, independientemente si aparecen explícitos junto al verbo o no.

Tales son:

Le pregunté una duda al profesor.

* Lo pregunté porque esperaba preguntas.

Le dije a Isabel que estaba guapísima.

* La dije (a Isabel) porque estaba harto de su conducta.

\section{CRITERIOS DE DELIMITACIÓN DEL OBJETO DIRECTO}

A. Porto Dapena (1994: 17) aduce dos tipos de caracterización del OD, llamado por algunos estudiosos implemento. La primera remite a la definición semántica; la segunda es de tipo formal. Según la primera el OD es un sustantivo o una palabra sustantivada sobre el cual recae directamente la acción verbal. Sin embargo, hay verbos de carácter estativo a las que esta visión no se puede aplicar. Es más, a menudo serán los sujetos de la oración los que verdaderamente sufren la acción, como en:

Juan padece una grave enfermedad.

Jan cierpi na poważną chorobę.

Hemos soportado muchas dificultades.

Znieśliśmy wiele trudności.

'La forma de dativo también es admitida: Le perdono porque lo hizo sin querer. 
Luisa tiene veinte años.

Luiza ma dwadzieścia lat.

Además abundan los verbos en que resulta muy problemático el reconocimiento adecuado de sus complementos a partir de su contenido semántico. A la luz de este criterio, el complemento del verbo ayudar muy bien puede considerarse directo como indirecto. No se sabe exactamente si éste recibe el resultado de la acción verbal, o bien es su beneficiario. De todos modos, el castellano le asigna el oficio de OD y el polaco, el de OI, vgr.:

Lo ayudé con sus tareas.

Pomogłem $m u$ przy zadaniach.

Por el contrario, con la interpretación española concuerda la forma del complemento del verbo sinónimo polaco wspomagać kogoś. El OD que lo acompaña indica que lo percebimos como el receptor de la acción efectuada por el sujeto. Así:

Wspomagałem ich $\mathrm{w}$ ich walce o wolność.

Los ayudé en su lucha por la libertad.

Si tomamos otros verbos como preguntar o enseñar, llegamos a la conclusión que el régimen casual atribuido por el polaco obedece mejor al criterio semántico que el español. Citemos a Porto Dapena (1994: 20):

El estudiante preguntó la duda al profesor.

El profesor enseña a sus alumnos la gramática.

Parece lógico que desde el punto de vista semántico son los sintagmas el profesor y sus alumnos los que deberían gozar del estatus de implemento. Lo confirma la posible transformación en sujeto de la oración pasiva:

El profesor fue preguntado.

Los alumnos son enseñados.

R. Cano (1992: 138-139) apunta al respecto que las construcciones de doble acusativo latino habian convertido el acusativo personal en complemento indirecto; así 'rogare/docere aliquem aliquid > rogarle/enseñarle algo'. Es digno de notar también que según el mismo autor diversos verbos latinos que regian, siempre o en ocasiones, dativo se hicieron transitivos en castellano; tales son ayudar y amenazar que actualmente exigen solo un acusativo.

En vista de las dificultades que supone la delimitación semántica de un OD, la mayoría de los linguístas modernos prefieren caracterizarlo desde presupuestos formales. Uno de ellos es el procedimiento expuesto arriba, es decir, la posibilidad de pasar OD a sujeto en la construcción pasiva. Se lo utiliza también en polaco para definir al OD. Pongamos más ejemplos: 
Matka kocha syna $=$ Syn jest kochany przez matkę

Król rządził miastem $=$ Miasto było rządzone przez króla ${ }^{2}$

Colón descubrió América $=$ América fue descubierta por Colón

No toleramos la doblez $=\mathrm{La}$ doblez no es tolerada por nosotros

Ciertamente, no siempre las oraciones resultantes de la transformación pasiva parecen normales, especialmente en español, el cual es poco amigo de la construcción ser + participio. En cualquier caso, aun pareciendo extrañas las vemos al menos como posibles y lógicas (M. Seco 1989: 107). No obstante, este método tampoco es perfecto por cuanto en ambas lenguas no faltan verbos transitivos que no admiten la transformación. He aquí algunos:

Tengo dolores de parto.

*Dolores de parto son tenidos por mí.

No sufro a tu profesor.

*Tu profesor no es sufrido por mí.

Mam wiele kłopotów.

*Wiele kłopotów jest mianych przeze mnie.

Nie znoszę obłudy.

*Obłuda nie jest znoszona przeze mnie.

Curiosamente algunas veces, también el OI admite la transformación en sujeto, en particular con verbos como preguntar, enseñar y perdonar. Ahora bien, se puede constatar que dichos verbos tienen otros complementos semánticos que formales. Así:

Yo le perdoné a María sus pecados.

Yo perdoné a María / María fue perdonada por mí.

Le pregunté al profesor la solución del problema.

Pregunté al profesor / El profesor fue preguntado por mí.

\section{LA PRONOMINALIZACIÓN DE LOS OBJETOS}

En definitiva, debido a dicha deficiencia, el criterio de transformación pasiva es sustituido preferentemente por otra caracterización formal, esto es, la citada pronominalización que consiste en la conmutación del objeto sustantivo mediante las formas átonas del pronombre personal. En opinión de muchos gramáticos, este recurso es decididamente la mejor vía para descubrir la verdadera naturaleza del adyacente en cuestión (A. Porto 1994: 19):

${ }^{2}$ De paso sea dicho que en la lengua polaca no siempre el OD viene expresado por un acusativo, sino que a veces se esconde bajo la forma de otros casos. El verbo rzqdzic, citado arriba, exige, por ejemplo, el ablativo miastem. 
Tengo dolores de parto $\sim$ Los tengo (OD)

No sufro a tu profesor $\sim$ No lo sufro (OD)

Rogué al crío que se calmara $\sim$ Le rogué que se calmara (OI)

Dicen que pega a su mujer $\sim$ Dicen que le pega (OI)

Esta prueba la utilizan con éxito los hablantes nativos españoles y su objetivo final será teórico, es decir, establecer el régimen casual de un verbo determinado. Los estudiantes de español como lengua extranjera, en cambio, en vista de su menor competencia lingüística, habrán primero de memorizar el régimen pronominal de los verbos castellanos cuyos complementos no conciertan con los polacos. Así, el objetivo alcanzado sería doble; uno práctico, es decir, el dominio de los pronombres personales átonos en función de objeto, y otro, teórico, resultante de la competencia linguística adquirida, servirá para la adecuada caracterización sintáctica de dichos objetos. Con el fin de facilitar la tarea para los alumnos polacos, aducimos una lista de verbos en cuestión empleados, cada cual, en una oración entera. Para evitar confusión, nos atenemos únicamente a la norma académica libre de vicios como leísmo y laísmo:

\section{Acompañar}

Todos los días lo acompañaba en sus salidas nocturnas.

Codziennie towarzyszył $m u \mathrm{w}$ jego nocnych eskapadach.

\section{Alegrar}

Cuando Marisol era pequeña le alegraban las flores.

Gdy Marisol była mała, cieszyły ja kwiaty.

\section{Amenazar}

Lo amenazaron con llamar a la policía.

Zagrozili $m u$, że zadzwonią na policję.

\section{Apasionar}

Le apasiona la música.

Pasionuje jq muzyka.

\section{Apenar}

$L e$ apenó mucho que se fuera sin despedirse.

Bardzo jq zabolało, że odjechał nie pożegnawszy się.

Avisar

Le avisé con tiempo de mi llegada.

Powiadomiłem ja na czas o moim przyjeździe.

\section{Asegurar}

Les aseguraron que no habrá ningún problema

Zapewnili ich, że nie będzie żadnego problemu. 


\section{Ayudar}

¿Porqué no los ayudáis si tenéis más suerte?

Dlaczego im nie pomagacie, jeśli macie więcej szczęścia?

\section{Comunicar}

Se lo comunicaremos enseguida.

Powiadomimy Pana o tym natychmiast.

\section{Contestar}

Los alumnos hacen preguntas y el profesor las contesta.

Uczniowie zadaja pytania, a nauczyciel na nie odpowiada.

\section{Costar}

Su amistad les costó disgustos.

Przyjaźń z nim kosztowała ich przykrości.

Doler

A mi compañero de clase le duele la garganta.

Mojego kolege z klasy boli gardło.

\section{Encantar}

No les encantan las aceitunas, prefieren las fresas.

Nie Iubią oliwek, wolą truskawki. (dosł. Nie zachwycają ich oliwki...)

\section{Enseñar}

Les enseñó a leer cuando tenían seis años.

Nauczył ich czytać, gdy mieli sześć lat.

\section{Entristecer}

Su partida le entristece mucho.

Jego wyjazd bardzo jq zasmuca.

\section{Entusiasmar}

No le entusiasma mucho el fútbol.

Nie zachwyca go za bardzo piłka nożna.

\section{Extrañar}

Le extrañó un poco aquella salida del viejo.

Zdziwił go trochę ten wyjazd starego.

\section{Hablar}

Un día Manolo le quiso hablar muy seriamente. (también: hablar con ella) Pewnego dnia Manolo chciał z nia porozmawiać poważnie.

\section{Informar}

Le informé al médico que viniera a verme cuanto antes.

Powiadomiłem lekarza, żeby przyszedł do mnie jak najprędzej.

\section{Impresionar}

$L e$ impresionó mucho verlo en uniforme.

Robiło na niej duże wrażenie widzieć go w mundurze. 
Interesar

A Ana no le interesan tus asuntos.

Annę nie interesuja twoje sprawy.

Interrumpir

Menos mal que esta noche nadie los interrumpirá.

Na szczęście tej nocy nikt im nie będzie przerywał.

\section{Llamar}

No lo llames por teléfono, el número está comunicando.

Nie dzwoń do niego, numer jest zajęty.

Mentir

A pesar de su gran confianza, Roberto les ha mentido descaradamente.

Pomimo ich wielkiego zaufania, Robert bezwstydnie okłamał $i c h$.

\section{Pedir}

Le pedí al alcalde la mano de su hija menor.

Poprosiłem burmistrza o rękę jego młodszej córki

\section{Pedir perdón}

Pídele perdón a tu padre.

Przeproś swojego ojca.

Pegar

Dicen que le pega a su mujer.

Mówią, że bije swoja zonę.

\section{Preguntar}

Pregúntale a tu hermano si viene a comer.

Zapytaj swego brata, czy przyjdzie na obiad.

\section{Rogar}

Es inútil rogarle al crío que se calme.

Bezskuteczne jest proszenie niemowlaka, żeby się uspokoił.

\section{Solicitar}

El año pasado le solicité una beca a aquella fundación.

W zeszłym roku starałem się w tej fundacji o stypendium.

\section{Sorprender}

Le sorprende que no lo sepas.

Dziwi $j q$ że tego nie wiesz.

Adviértase un nutrido grupo de verbos que requieren solo un dativo, p.ej.: alegrar, sorprender, impresionar, enfadar, apenar, etc. En la oración, ordinariamente se anteponen al sujeto y expresan sobre todo estados anímicos humanos. El valor del complemento indirecto se hace más visible en una construcción sinonímica. Así: 
Le entusiasma el fútbol $=\mathrm{El}$ fútbol le provoca entusiasmo

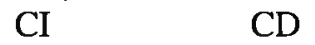

Le alegra tu visita $=$ Tu visita $l e$ provoca alegría

CI $\quad \mathrm{CD}$

$L e$ enfada tu comportamiento $=$ Tu comportamiento $l e$ causa enfado

CI $\quad \mathrm{CD}$

Esta lista que se ha establecido como una selección de los verbos más comunes no excluye, ni mucho menos, la existencia de otros, cuyos objetos no se conforman con el uso polaco. Por lo tanto, sería recomendable alargarla y adjuntarla ya completa a métodos de gramática para los polacos. Las transgresiones a la norma etimológica: leísmo, laísmo y loísmo (uso vulgar de la forma de acusativo en vez de dativo), presentes en el español peninsular, vienen embrollando tanto el sistema de los pronombres personales, que apenas hay hablantes extranjeros que sepan atribuirles siempre y sin falta sus verdaderas funciones oracionales. Por si fuera poco, la inseguridad que sienten al respecto los estudiantes de español se acompaña de la falta absoluta de este tipo de datos en los diccionarios, tanto bilingües polaco-españoles como monolingües publicados en España. Además, la situación no es nada mejor en diccionarios de español que se publican en otros países. Incluso obras de tanto prestigio como The Oxford Spanish Dictionary de 1994 ofrecen algunas veces formas defectuosas de pronombres personales objeto, por ejemplo:

*Su partida la entristeció mucho.

(en vez de $l e$ )

* No lo entusiasma el fútbol. (en vez de $l e$ )

* Los enseñan a buscar drogas. (en vez de les)

Sea como fuere, vista la complejidad de la materia, es hora de que finalmente la problemática del régimen casual de los complementos verbales españoles tenga mayor resonancia en las obras lingüísticas de consulta.

\section{REFERENCIAS}

A larcos Llorach, E. (1994), Gramática de la lengua española, Madrid: Espasa Calpe.

Alcina Franch, J., Blecua J.M. (1975), Gramática española, Barcelona: Ariel.

Cano Aguilar, R. (1992), El español a través de los tiempos, Madrid: Arco/Libros.

Porto Dapena, J.A. (1994), Complementos argumentales del verbo: directo, indirecto, suplemento y agente, Madrid: Arco/Libros.

Seco, M. (1989), Gramática esencial del español. Introducción al estudio de la lengua, Madrid:

Espasa Calpe.

The Oxford Spanish Dictionary (1994), eds. B. Galimberti, R. Russel, Oxford-New York-Madrid:

Oxford University Press. 